AGH DRILLING, OIL, GAS • Vol. 30 • No. $1 \cdot 2013$

http://dx.doi.org/10.7494/drill.2013.30.1.199

\author{
Dan-Paul Ştefănescu*, Ioana Vlasin*
}

\title{
A NEW APPROACH OF MATURE GAS FIELDS REHABILITATION FROM TRANSYLVANIAN BASIN (ROMANIA)
}

\section{INTRODUCTION}

The mature gas fields rehabilitation represents a permanent concern of the Romgaz technical management, being considered one of the major priority of the development strategy of our company.

The most part of our gas fields located in the geological unit of Transylvanian Basin are characterized by an advanced stage of exploitation, with a long production history and high cumulatives, having a current recovery factors of more than $60-70 \%$. This status gives them the name „mature fields”, or „brownfields” concepts logically associated with another notion, called „rehabilitation”, also very frequently used in the world oil and gas industry.

As the production decreasing became actually more obviously, due to the natural energetic decline of the reservoirs, the only viable solution to overcome this, consists in finding technical, commercial and operational best practices designed to develop incremental production and access additional reserves.

This issue has preoccupied also the Romgaz technical team to implement and develop in the same time a new management strategy of this type of reservoirs, setting up a special department for designing the rehabilitation projects for our mature gas fields.

\section{SOME THEORETICAL CONSIDERATIONS REGARDING THE REHABILITATION PROCESS}

Of course, the rehabilitation process is not a simple one, because requires a more complex approach of an integrated project team, deeply involved in the subsurface management of the reservoirs and also in designing the more efficient surface facilities.

* SNGN Romgaz S.A. Mediaş 


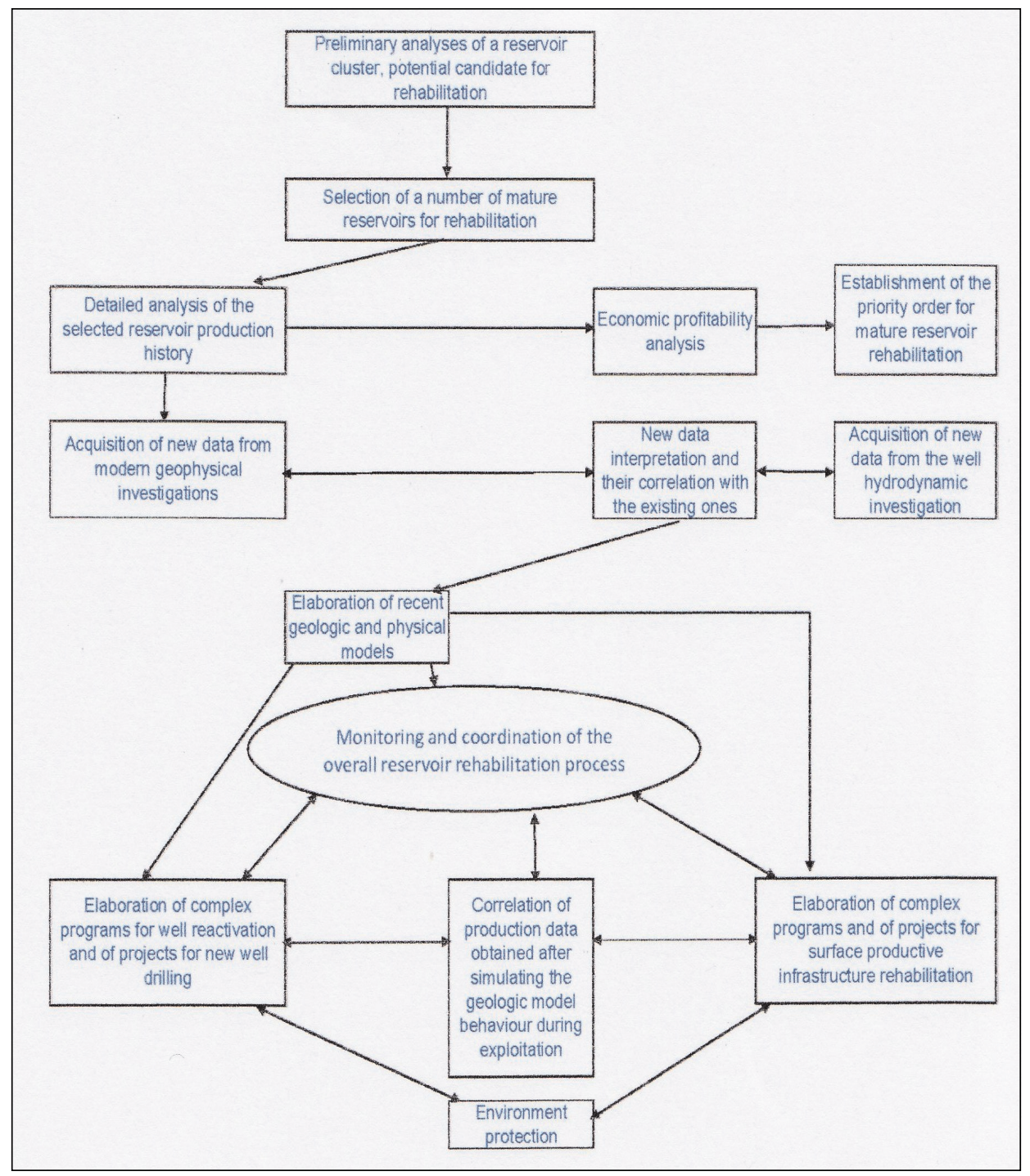

Fig. 1. The stages of mature gas field rehabilitation

This actually means elaboration a detailed technical - economical documentation with computation the initial geological resources and estimation the exploitation performances of that reservoirs.

In fact, a lot of technical procedures and daily routine practices are also applied, but in a particular manner, depending on the current status of the wells.

The idea is that rehabilitation is a more general process, designed to improve reservoir overall performances through complex well reactivation operations extended to a large 
number of wells, in a well defined period of time, along with surface infrastructure modernization, in order to eliminate, as much as possible, the pressure losses. This is the reason why, most of the times, the budget for in integrum rehabilitation of a gas structure is a very consistent one

Schematically, an in integrum mature gas fields rehabilitation process consists in performing more steps,starting with the reconsidering of the geological model, based on the new information acquired, in a very strong correlation with the physical model of the reservoir, together with designing a complex workover plan of the wells, and upgrading the surface facilities network. The cash flow, risk analyses and environmental protection issues are also approached.

Speaking about the geological model reconsidering, it means in fact a reconfiguration or reconstruction the geological model, in a new version, based on the acquisition, processing, interpretation and correlation the whole geological data base with production history and other information, in order to reevaluate the initial gas in place,the geological reserves and production forecast with much more accuracy than in a classical version.

\section{CASE STUDIES}

In this context, the new information offered by the 3D seismic acquisition and also by the cased logging campaign for gas saturation evaluation represented a valuable data base for reconfiguration the geological and physical models of some major gas fields from Transylvanian Basin, which allowed identifying the new opportunities for a future development. The last generation software have been used for geological modeling and reservoir simulation.

The paper reveals some of our experiments related to this topic, which are described in details. One example is referring to the results obtained after deepening of one well in Laslau Mare gas field, as part of the Association Project Romgaz-Schlumberger, started in 2003 and the other one is related to a new production well drilled on other mature gas field, Nades -Prod - Seleus, both in Transylvanian Basin.

\subsection{Deepening the well $X$ LM}

The well is located in the eastern part of the field Laslau Mare and was produced from layer Bgl XI + XII with a low flow rate, less than $3000 \mathrm{stcm} /$ day.

The proposal for deepening to the layer Bn XIII + XIV has been justified by a series of geological, stratigraphic and also production criteria as follows:

- A high volume of undrained resources at level Bn XIII + XIV and a considerable volume of probable reserves which could be accessed by the well.

- The most appropriate wells in production located at considerable distances (more than $1 \mathrm{~km}$ ) and with high cumulative productions, indicate that area can be considered undrained and also the existence of good flowing parameters of the reservoirs. 
- The most appropiate wells were only tested, one with $22.000 \mathrm{stcm} /$ day and the other one with ,no flow”, due to a damage caused by the perforation job.

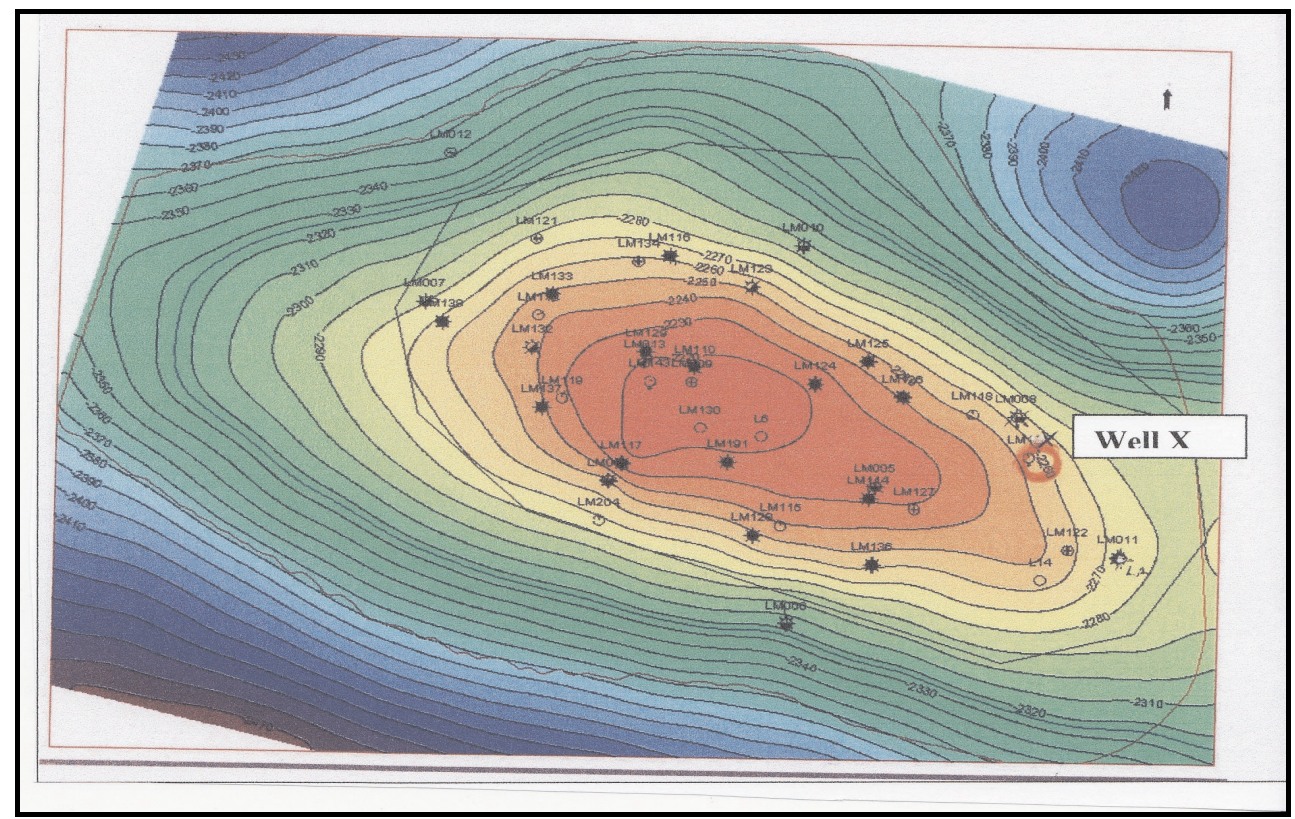

Fig. 2. Structural map - top layer XIII a

- The synthetic lithological column is represented by an alternation of porous - permeable formations as: sandstones, silty clays, siltites.

- From the stratigraphic section A - A' (with direction NNW - SSE) with the reference plane the top of Bn XIIIa, can be noticed the continuity of the porous - permeable bodies. Following the geophysical logs features, it's obvious the lateral continuity, despite the low resolution of the SP (spontaneous potential) curve, due to the lithological composition (high shale volume) which attenuates the curve deflection. On the other hand, the resistivity curves expose great values (more than $5 \mathrm{Wm}$ ), being a good indicator of the gas content. The nearby production wells expose the same characteristics on the logs.

- The structural section B-B' has the same direction as the stratigraphic section A-A' and cross the same wells. From this section and also from the structural map on the top of layer Bn XIIIa, is noticed that the well $\mathrm{X}$ is located on the most favorable position, $10 \mathrm{~m}$ higher isobathically than one well and $23 \mathrm{~m}$ than the other one.

- The 3D seismic acquisition offered more informations related especially to the facies model, without a special contribution to the structural model, which remained the same as the previous one.

- The cash flow analyze was also positive and indicated a profitable investment. 


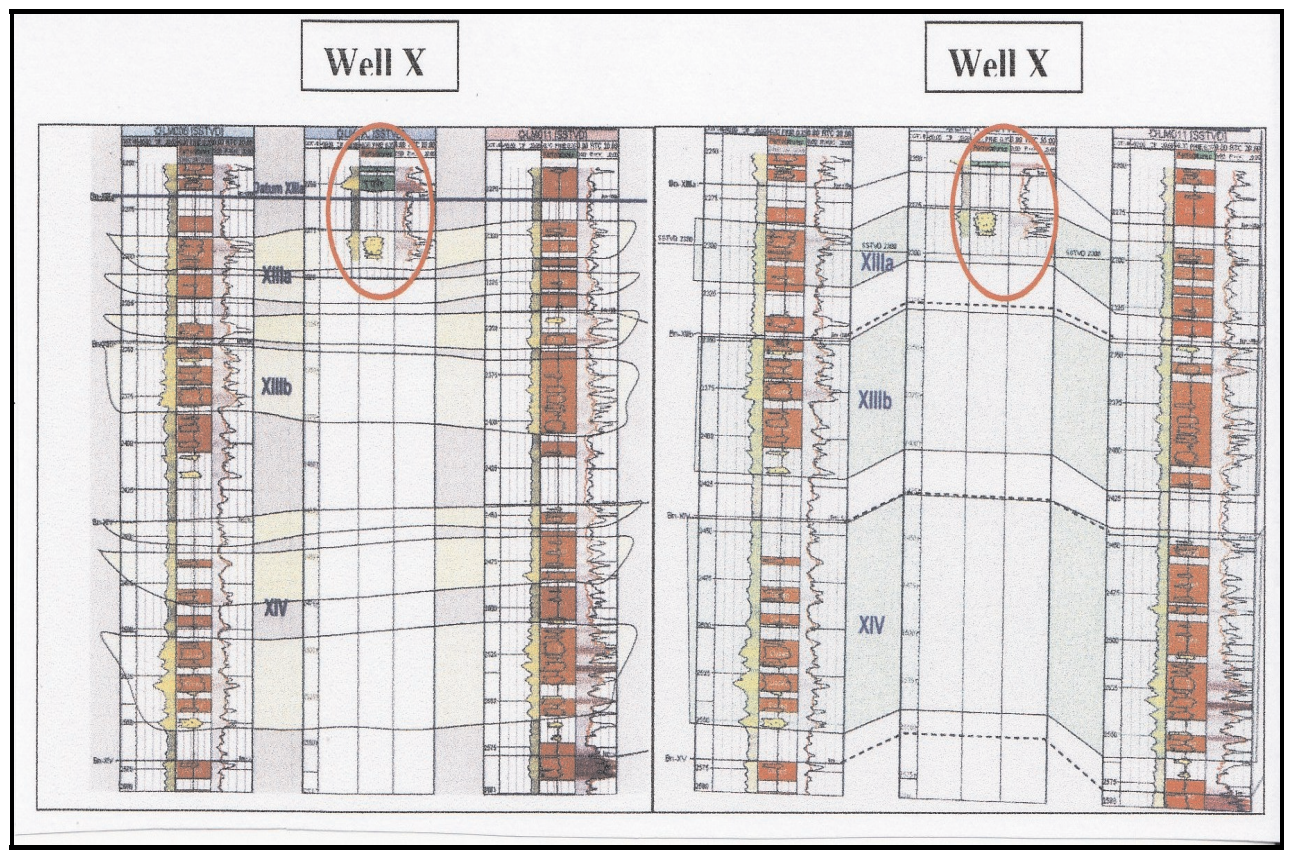

Fig. 3. Stratigraphic section $A-A^{\prime}$

Fig. 4. Structural section B-B'

Based on the above premises, the well was deepened $280 \mathrm{~m}$, a $3 \frac{1 / 2}{2}$ in liner was set and cemented on the whole length and the layer Bn XIII + XIV was perforated with 2 in Deep penetration guns, in formic acid.

The result was a gas flow rate of $17.300 \mathrm{stcm} /$ day. The well is producing now with the same rate.

Another well was also deepened to this layer and in the near future will be drilled two new infill wells As part of the Integrated Project Management team rehabilitation process, more other practices have been applied in the field as workover jobs, coiled tubing acid jobs, with good results, nitrogen displacements, upgrading the surface facilities network etc.

\subsection{Designing a new well Y NP}

This case study is related to another depleted gas field located also in Transylvanian Basin in the southern part, where the geological model was radically changed and reconfigured based on the new 3D seismic acquisition. If the previous model was indicated an unfolded brachianticline, in the new vision, the structural architecture illustrated a complex network of faults, which separate more blocks (called „segments”). Regarding the geological and facies model, it can be noticed a very detailed correlation, each layer being divided in more package, in comparison with the previous geological image, which was more roughly. This type of evaluation allowed a more accurate analyze of each hydrodynamic unit, 
in terms of gas saturation limit (gas - water contact) degree of depletion, detecting by-passed zones etc. Based on this considerations, a new well was designed, located in the segment I, and justified by a lot of geological and production criteria.

We mention that the new well was initially designed as a deviated well, and completed to be dual for exploitation two layers: Sa VIII and Sa VI. Finally it was founded a new location in the field, to be drilled as a vertical well.

Briefly we try to expose the reasons for opening the both layers:

\section{Sa VIII (Fig. 5)}

- Considerable volume of actual resources at the level VIII a, b, c (respectively at the level of segments I, II, III), with actual low recovery factors (between $14 \%$ and $56 \%$ ). The reason for this is explained by:

- more wells which produced from the segments II and III were abandoned due to the landslides,

- a single well is producing at the level of segment I but only from zones VIII $\mathrm{d}$ and VIII e,

- the zones VIIIa and VIIIb at the level of segments I and II have not been tested (only package VIIIa was tested in a single well with initial pressure and a very high flow-rate, more $200.000 \mathrm{stcm} /$ day).

- The reservoir pressures at the level of segment I (zones WIIIa and VIIIb) are expected to be higher than average pressure of the objective, but lower than the initial pressure.

- The risk to drill the well to level VIII a / segment I, is represented by the possibility to have a low productivity due to the lithology (more clays in the zone VIII a from north to south in the segment II, and the clay content is also higher in the segment I in one well), but we could have good sands too.

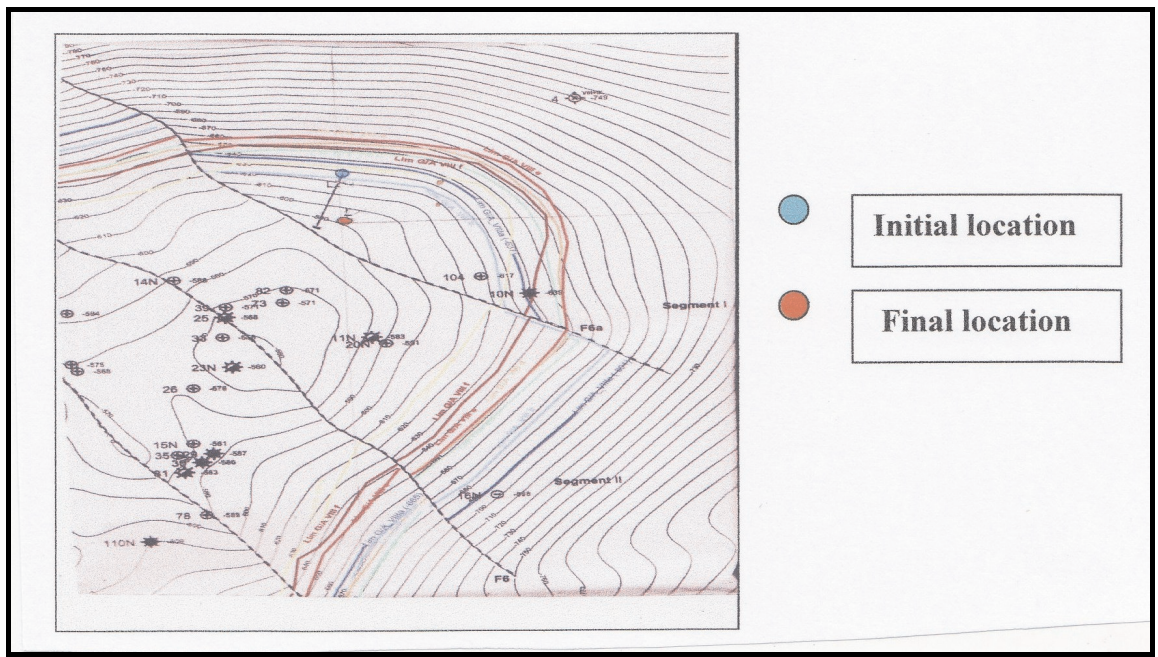

Fig. 5. Structural map at top layer Sa VIII - fragment 


\section{SaVI (Fig. 6)}

- The resources allocated to the segments I and II are still high the „recovery factor” being less than $50 \%$. The reason for this is:

- only two wells have produced in this area and one well is producing with a higher reservoir pressure than average.

- The risk is represented by the depletion degree in the area, which could be higher due to one well, located at a distance of $600 \mathrm{~m}$, which had a more considerable cumulative production and also the possibility to have water in the lower section of layer VI.

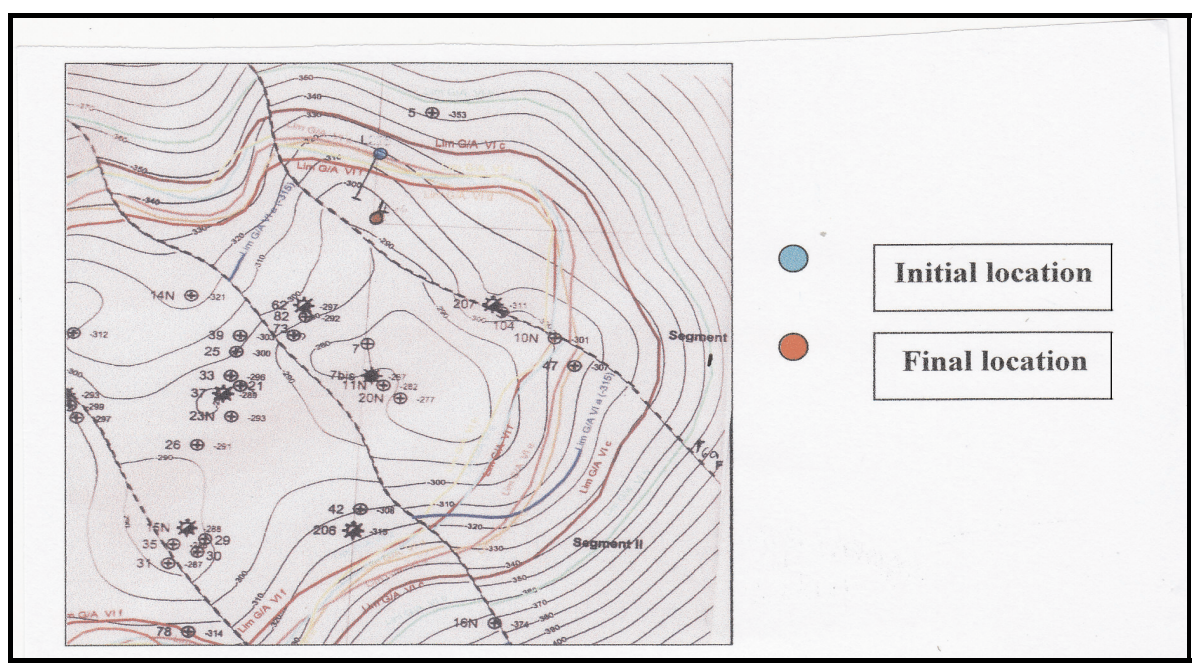

Fig. 6. Structural map at top layer Sa VI - fragment

As we mentioned before, the 3D seismic acquisition offered a lot of information which support the new well designing, at the level of segment, in terms of discontinuities caused by tectonics (structural factors), respectively faults and also facies variations:

- According to the seismic profiles, the faults F6a and F6 separate the eastern segments I and II from the central and western blocks, with a recovery factor more than $70 \%$ (Fig. 9). These tectonic discontinuities are indicated also by the maps with seismic attribute variance (Fig. 7, 8).

- The facies discontinuities are also reflected by the seismic sections (Fig. 10).

Even if these discontinuities don't seal the reservoirs from the segment I can create a ,stop” on gas flowing, thus resulting zones with different degrees of depletion.

- in case of negative results at Sa VIII and VI, it was taken into account the possibility of retrieval the well to the upper layers, with still have high actual resources;

- the cash flow analyze and production forecast were also positive and optimistic. 


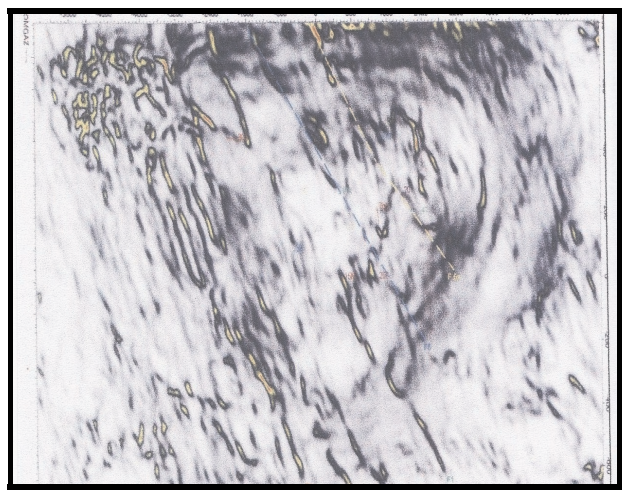

Fig. 7. Horizontal section through seismic cube 3D for layer VI with variance attribute (discontinuities)

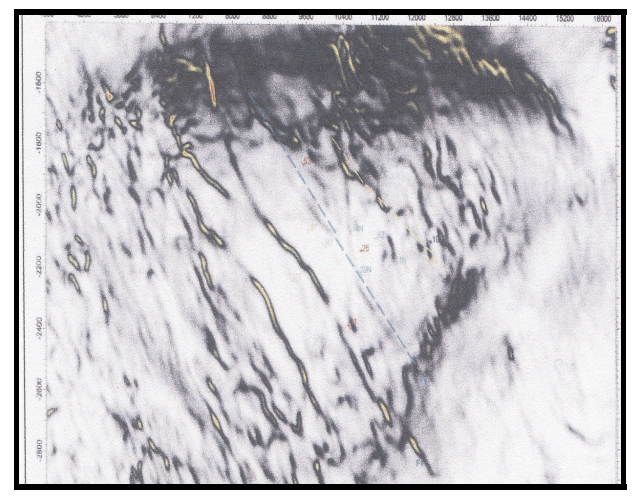

Fig. 8. Horizontal section through seismic cube 3D for layer VIII with variance attribute (discontinuities)

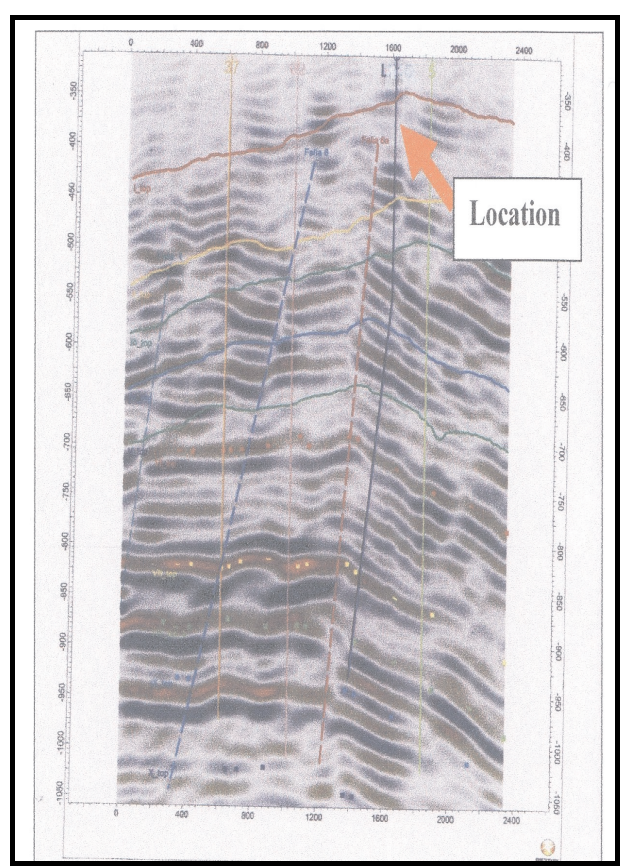

Fig. 9. Section through seismic cube Tectonic discontinuitie

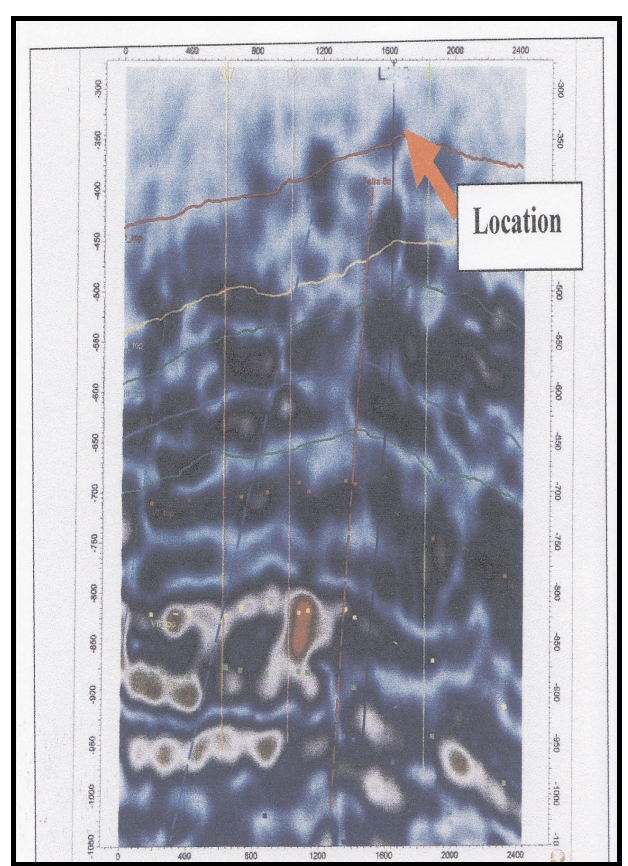

Fig. 10. Section through seismic cube Facies discontinuities

We mention that new location was drilled in good conditions, and was tested the layer VIII, with 2 in Deep penetration guns, resulting a gas flow rate of about $70.000 \mathrm{stcm} /$ day and a static wellhead pressure of 86 bars. 
For the moment, the well wasn't completed at layer Sa VI as a dual well due to the possibility to be tested in the future also the layer VII, which was previously converted in an underground gas storage.

\section{CONCLUSIONS AND PROPOSALS}

- The mature gas fields rehabilitation represents for Romgaz company a target of major interest.

- With all the risks that would involved, a new approach of the mature gas fields rehabilitation, can assure a rational capitalization of the entire national amount of geological resources and reserves.

- The encouraging obtained results represent a certain premise to continue with new rehabilitation projects on the other mature gas fields, which will be implemented in the near future.

- Only an accurate technical - economic analysis of the risk factors, will determine, from case to case, most efficient solution approach in practice.

\section{REFERENCES}

[1] Ştefănescu D.-P., Introduction to the mature natural gas reservoir rehabilitation Theory and case studies. Lucian - Blaga, the Publishing House of Lucian Blaga University, Sibiu 2012.

[2] Ştefănescu D.-P., Şuţoiu F., Vlasin I. Side-track, reentry and deepening. Regional Energy Forum, Neptun, 15-17 June, 2010.

[3] **** Romgaz archive. 